\title{
Faktor Pengaruh Purchase Intention Berdasarkan Perspektif Konsumen pada Aplikasi Mobile Online Travel Booking
}

\author{
Handrie Noprisson1, Marissa Utami2 \\ 1 Fakultas Ilmu Komputer, Universitas Mercu Buana \\ Jl. Raya Meruya Selatan, Kembangan, Jakarta, Indonesia, 11650 \\ E-mail: handrie.noprisson@mercubuana.ac.id \\ 2 Fakultas Teknik, Universitas Muhammdiyah Bengkulu \\ Jl. Bali, Kota Bengkulu, Indonesia, 38119
}

\begin{abstract}
The development of the online travel booking business must be followed by increased revenue to maintain the trust of business partners such as investors and merchants. Increased purchases by consumers can be supported by several factors, one of which is purchase intention from a consumer perspective. This study looks at how the influence of a consumer perspective based on trust, perceived value, brand image, product diagnosicity on increasing purchase intention for online travel booking applications. Stages of research include data collection, data processing using SMARTPLS, interpretation of data processing results and drawing research conclusions. As a result of the study, the trust factor has the influence on purchase intentions with a t-value of 8.280 . The perceived value influences purchase intentions in the online travel booking application with a t-value of 7.091. Brand image also has an influence on purchase intention with a score of 5.253.
\end{abstract}

Abstrak-Berkembangnya bisnis online travel booking ini harus diikuti dengan peningkatan revenue untuk mempertahankan kepercayaan partner bisnis seperti investor dan merchant. Peningkatan pembelian oleh konsumen ini dapat didukung oleh beberapa faktor, salah satunya purchase intention dari perspektif konsumen. Penelitian ini melihat bagaimana pengaruh perspektif konsumen berdasarkan trust, perceived value, brand image, product diagnosicity terhadap peningkatan purchase intention untuk aplikasi online travel booking. Tahapan penelitian antara lain pengumpulan data, pemrosesan data menggunakan SMARTPLS, interpretasi hasil pemrosesan data dan penarikan kesimpulan penelitian. Sebagai hasil penelitian, faktor kepercayaan (trust) memiliki pengaruh terhadap niat beli (purchase intention) dengan t-value 8,280. Nilai yang dirasakan (perceive value) mempengaruhi niat pembelian (purchase intention) dalam aplikasi pemesanan perjalanan online dengan t-nilai 7,091. Citra merek (brand image) juga memiliki pengaruh terhadap niat beli (purchase intention) dengan skor 5,253.

Keywords - consumer analysis, purchase intention, online travel booking, SMARTPLS

\section{Pendahuluan}

Pertumbuhan bisnis di bidang online travel booking meningkat setelah banyak investor dan merchant yang bersedia untuk bekerjasama. Sejak pertama kali diluncurkan, salah satu aplikasi online travel booking telah mampu memperoleh lebih kurang 500.000 pesanan [1].

Berkembangnya bisnis online travel booking ini harus diikuti dengan peningkatan revenue untuk mempertahankan kepercayaan investor dan merchant yang telah bersedia untuk berkerja sama. Peningkatan purchase ini dapat didukung oleh beberapa faktor, salah satunya purchase intention dari perspektif konsumen. Penelitian ini akan melihat bagaimana pengaruh perspektif konsumen berdasarkan kepercayaan (trust), persepsi nilai (perceived value), citra merk (brand image), dan product diagnositicy terhadap peningkatan purchase intention pada aplikasi online travel booking.

Berdasarkan riset sebelumnya, penelitian mengenai kepercayaan (trust) telah pernah dilakukan oleh Wu et al. [2] dan Mansour et al. [3].
Sedangkan, penelitian yang dibahas oleh McCole et al. (2010) berkaitan dengan pengaruh trust pada sikap (attitudes) terhadap online purchasing dengan efek moderasi dari faktor privacy dan security [4].

Kepercayaan (trust) adalah salah satu fokus utama dalam hubungan pembeli-penjual, peran kepercayaan dalam hubungan pertukaran sosial telah menjadi objek penelitian [3]. Menurut $\mathrm{Wu}$ et al. [2], semakin banyak pelanggan mempercayai sebuah situs web, semakin rendah risiko transaksi online yang dirasakan, dan semakin besar keinginan untuk membeli di situs web tersebut.

Kim et al. membahas mengenai pengukuran pengaruh perceived value pada internet shopping [5]. Lebih lanjut, penelitian mengenai value baik nilai utilitarian (utilitarian value) dan nilai pengalaman (experiential value) telah dilakukan oleh Lee and Overby (2004). Sedangkan value, menurut Zeithaml (1988), meskipun ada ekspresi konsumen yang berbeda nilai, nilai yang dirasakan dapat ditangkap dalam satu definisi keseluruhan sebagai penilaian keseluruhan konsumen tentang kegunaan produk/layanan berdasarkan persepsi 
tentang apa yang diterima dan apa yang diberikan (misalnya, pertukaran antara manfaat yang dirasakan (perceived benefits) dan biaya yang dirasakan (perceived cost)).

Penelitian mengenai brand image telah dilakukan oleh Ryu et al. [8], Aghekyan-Simonian et al. [9] dan Anwar et al. [10]. Definisi dari brand image sendiri adalah determinan yang mempengaruhi persepsi subyektif pelanggan dan perilaku konsekuen [8]. Semakin baik sebuah brand image, maka semakin positif sikap konsumen terhadap produk tersebut [9]. Lebih lanjut, sebuah brand image mendorong konsumen dalam mengenali kebutuhan dan keinginannya terkait merek dan membantu konsumen membedakan merek dari pesaing lainnya [10].

Penelitian mengenai product diagnosity telah dilakukan oleh Buaprommee and Polyorat (2016). Untuk mendukung keberlangsung bisnis perlu diketahui faktor-faktor yang berpengaruh secara signfikan terhadap purchase intention melalui aplikasi online travel booking salah satunya product diagnosticity (Buaprommee and Polyorat 2016).

Berdasarkan latar belakang diatas, penelitian ini akan melakukan penelitian mengenai analisis faktor purchase intention pada online travel booking berdasarkan kepercayaan (trust), persepsi nilai (perceived value), citra merk (brand image), dan product diagnosity terhadap peningkatan purchase intention.

\section{Studi Literatur}

Penelitian mengenai online travel booking telah dilakukan oleh [12], [13], [14] dan [15] dengan fokus dibeberapa faktor pengaruh atau pendukung. Conyette (2011) membahas variabel socio dan psychographic menggunakan Theory of Reasoned Action (TRA).

Penelitian oleh Oktivera dan Wirawan (2015) membahas mengenai pengaruh strategi digital marketing terhadap cara pandang konsumen terhadap penggunaan online travel booking. Pada tahun 2016, Wang (2016) membahas mengenai tentang pengaruh electronic word-of-mouth terhadap pengambilan keputusan dalam melakukan online travel booking. Sedangkan Jamilah and Handayani (2016) membahas mengenai brand community terhadap brand loyalty pada aplikasi online travel booking.

\section{Metode Penelitian}

Tahapan penelitian yang dilakukan secara umum dapat dilihat pada Gambar 1 berikut ini.

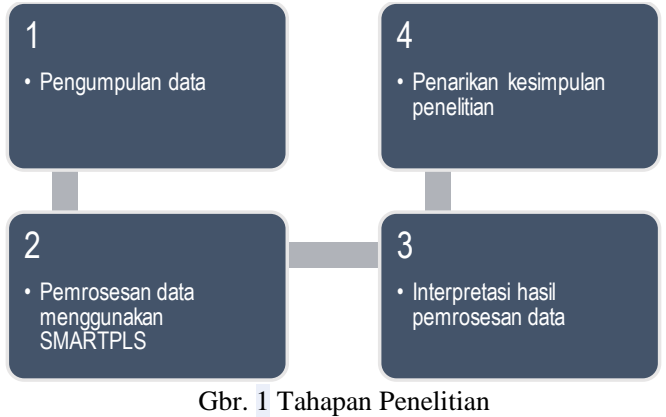

Berdasarkan gambar diatas, uraian mengenai setiap tahapan penelitian dapat diuraikan sebagai berikut:

1. Tahap Ke-1

Tahap pertama dilakukan pengumpulan data dengan menyebarkan kuesioner kepada responden yang pernah menggunakan online travel booking. Target responden dari penelitian ini adalah 1000 responden.

2. Tahap Ke-2

Tahap kedua data yang berhasil didapatkan kemudian dieleminasi jika data tersebut kurang lengkap sebelum diolah menggunakan model penelitian dengan bantuan SmartPLS menggunakan pendekatan SEM-PLS.

3. Tahap Ke-3

Tahap selanjutnya adalah interpretasi hasil pengolahan statistik sebelum ditarik kesimpulan bagaimana hasil analisis faktor purchase intention pada online travel booking berdasarkan kepercayaan (trust), persepsi nilai (perceived value), citra merk (brand image), dan product diagnosity terhadap peningkatan purchase intention. Untuk melakukan pemrosesan data, pemodelan faktor yang digunakan dapat dilihat pada Gambar 2 berikut.

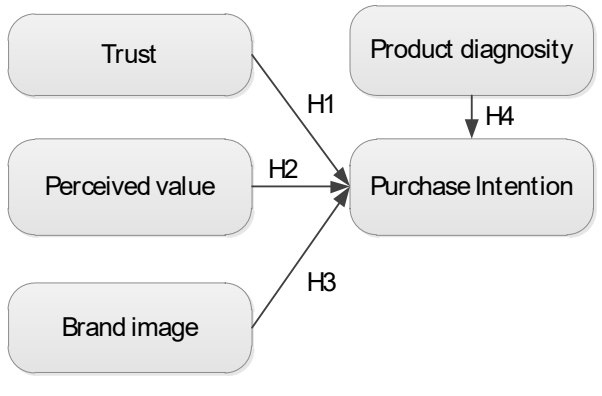

Gbr. 2 Model Penelitian

Berdasarkan model penelitian, hipotesis yang akan diuji antara lain:

H1. Trust memiliki pengaruh positif terhadap purchase intention

H2. Perceived value memiliki pengaruh positif terhadap purchase intention

H3. Brand image memiliki pengaruh positif terhadap purchase intention

H4. Product diagnositicy memiliki pengaruh positif terhadap purchase intention 


\section{Tahap Ke-4}

Penarikan kesimpulan menggunakan t-test bentuk two-tails untuk membuktikan hipotesis.

\section{Hasil Penelitian}

Tahap pertama dilakukan pengumpulan data dengan menyebarkan kuesioner kepada responden yang pernah menggunakan online travel booking. Target responden dari penelitian ini awalnya adalah 1000 responden, namun data yang valid hanya 984 data dengan hasil sebagai berikut.

TABEL I

DATA PENELITIAN

\begin{tabular}{|c|c|c|c|}
\hline \multicolumn{2}{|c|}{ Kategori } & Jumlah & $\%$ \\
\hline \multirow{2}{*}{$\begin{array}{l}\text { Jenis } \\
\text { Kelamin }\end{array}$} & Laki-laki & 481 & $48.88 \%$ \\
\hline & Perempuan & 503 & $51.12 \%$ \\
\hline \multirow[t]{5}{*}{ Umut } & $<21$ & 467 & $47.46 \%$ \\
\hline & $21-30$ & 480 & $48.78 \%$ \\
\hline & $31-40$ & 23 & $2.34 \%$ \\
\hline & $41-50$ & 12 & $1.22 \%$ \\
\hline & $>51$ & 2 & $0.20 \%$ \\
\hline \multirow[t]{4}{*}{ Pendidikan } & SMA & 511 & $51.93 \%$ \\
\hline & Diploma & 95 & $9.65 \%$ \\
\hline & Sarjana & 357 & $36.28 \%$ \\
\hline & Pasca Sarjana & 21 & $2.13 \%$ \\
\hline \multirow[t]{5}{*}{ Gaji } & $<$ Rp. 2000.0000 & 506 & $51.42 \%$ \\
\hline & $\begin{array}{l}\text { Rp. } 2000.0000- \\
\text { Rp. } 3000.0000\end{array}$ & 150 & $15.24 \%$ \\
\hline & $\begin{array}{l}\text { Rp. } 3000.0000- \\
\text { Rp. } 4000.0000\end{array}$ & 198 & $20.12 \%$ \\
\hline & $\begin{array}{l}\text { Rp. } 5000.0000- \\
\text { Rp. } 6000.0000\end{array}$ & 70 & $7.11 \%$ \\
\hline & > Rp. 6000.0000 & 60 & $6.10 \%$ \\
\hline \multicolumn{2}{|l|}{ Total } & 984 & $100 \%$ \\
\hline
\end{tabular}

Penelitian ini menggunakan SmartPLS untuk mendukung analisis data dan mendapatkan hasil penelitian. Hasil penelitian akan menjawab pertanyaan penelitian untuk memahami implikasi hipotesis. Untuk validasi structural model, riset ini menggunakan prosedur bootstrap resampling berdasarkan partial least squares (PLS) dengan memproses 984 data menggunakan model penelitian di bawah ini.

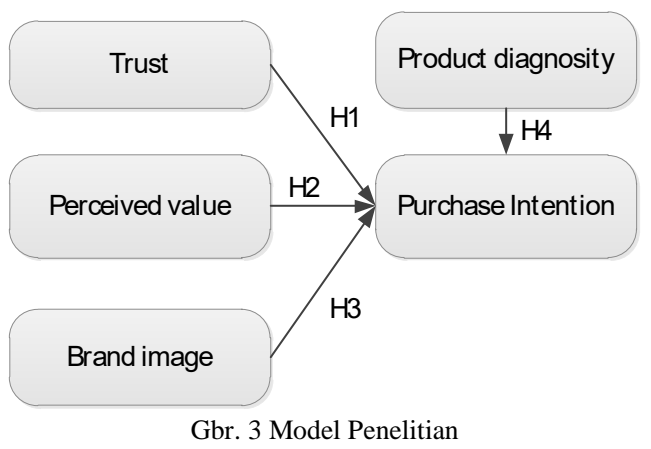

Selain itu, untuk memvalidasi validitas konvergen digunakan analisis faktor loading. Skor faktor loading harus di bawah 0,7 poin. Sedangkan, untuk memastikan model reliability, penelitian menggunakan indikator composite reliability $(\mathrm{CR})$, cronbach's alpha (CA) dan average extracted variance (AVE) dengan skor harus lebih besar dari 0,7 [16], [17] [18], [19]. Berdasarkan hasil faktor loading, semua atribut memenuhi syarat seperti yang ditunjukkan pada tabel berikut ini.

TABEL II

LOADING FACTOR

\begin{tabular}{|l|l|r|}
\hline Faktor & Attribute & Value \\
\hline Perceive Value & PEV1 & 0.829 \\
\cline { 2 - 3 } & PEV2 & 0.874 \\
\cline { 2 - 3 } & PEV3 & 0.867 \\
\hline Purchase Intention & PUI1 & 0.856 \\
\cline { 2 - 3 } & PUI2 & 0.851 \\
\cline { 2 - 3 } & PUI3 & 0.881 \\
\cline { 2 - 3 } & PUI4 & 0.870 \\
\hline Trust & TRT1 & 0.836 \\
\cline { 2 - 3 } & TRT2 & 0.868 \\
\cline { 2 - 3 } & TRT3 & 0.880 \\
\hline Brand Image & BI1 & 0.839 \\
\cline { 2 - 3 } & BI2 & 0.848 \\
\cline { 2 - 3 } & BI3 & 0.834 \\
\cline { 2 - 3 } & BI4 & 0.623 \\
\cline { 2 - 3 } & BI5 & 0.820 \\
\hline Product Diagnosicity & PD1 & 0.879 \\
\cline { 2 - 3 } & PD2 & 0.86 \\
\cline { 2 - 3 } & PD3 & 0.834 \\
\hline
\end{tabular}

Untuk memastikan model reliability, penelitian ini menggunakan composite reliability (CR), cronbach's alpha (CA) and average extracted variance (AVE) dengan skor harus lebih besar dari 0,7. Berdasarkan hasil pada Tabel 3, semua indikator telah memenuhi syarat.

TABEL III

MODEL RELIABILITY TESTING

\begin{tabular}{|c|c|c|c|c|}
\hline Faktor & CA & rho_A & CR & AVE \\
\hline $\begin{array}{c}\text { Perceived } \\
\text { Value }\end{array}$ & 0.819 & 0.824 & 0.892 & 0.734 \\
\hline $\begin{array}{c}\text { Purchase } \\
\text { Intention }\end{array}$ & 0.887 & 0.888 & 0.922 & 0.747 \\
\hline Trust & 0.826 & 0.826 & 0.896 & 0.742 \\
\hline Brand Image & 0.853 & 0.865 & 0.896 & 0.636 \\
\hline $\begin{array}{c}\text { Product } \\
\text { Diagnosticity }\end{array}$ & 0.736 & - & 0.893 & 0.821 \\
\hline
\end{tabular}

Penelitian ini menggunakan 0,05 tingkat signifikan dengan two-tails untuk pengujian hipotesis. Berdasarkan hasil analisis data, faktor kepercayaan (trust) memiliki pengaruh terhadap niat beli (purchase intention) dengan t-value 8,280. Nilai yang dirasakan (perceive value) mempengaruhi niat pembelian (purchase intention) dalam aplikasi pemesanan perjalanan online dengan t-nilai 7,091. Citra merek (brand image) juga memiliki pengaruh terhadap niat beli dengan skor 5,253. 
TABEL IV

HASIL UJI HIPOTESIS

\begin{tabular}{|c|c|c|c|c|c|}
\hline Hypothesis Testing & $\begin{array}{c}\text { Original } \\
\text { Sample (O) }\end{array}$ & $\begin{array}{c}\text { Sample Mean } \\
(\mathbf{M})\end{array}$ & $\begin{array}{c}\text { Standard Deviation } \\
\text { (STDEV) }\end{array}$ & $\begin{array}{c}\text { T Statistics } \\
(\text { O/STDEV })\end{array}$ & P Values \\
\hline $\begin{array}{c}\text { Perceived Value -> } \\
\text { Purchase Intention }\end{array}$ & 0.310 & 0.312 & 0.044 & 7.091 & 0.000 \\
\hline $\begin{array}{c}\text { Trust -> Purchase } \\
\text { Intention }\end{array}$ & 0.336 & 0.335 & 0.041 & 8.280 & 0.000 \\
\hline $\begin{array}{c}\text { Brand Image -> } \\
\text { Purchase Intention }\end{array}$ & 0.184 & 0.184 & 0.035 & 5.253 & 0.000 \\
\hline $\begin{array}{c}\text { Product Diagnosticity -> } \\
\text { Purchase Intention }\end{array}$ & 0.45 & 0.449 & 0.032 & 13.992 & 0.000 \\
\hline
\end{tabular}

\section{Kesimpulan}

Sebagai kesimpulan, berdasarkan analisis data responden sebanyak 984 dengan menggunakan SMARTPLS dapat diketahui bahwa faktor kepercayaan (trust) memiliki pengaruh terhadap niat beli (purchase intention) dengan t-value 8,280. Nilai yang dirasakan (perceive value) mempengaruhi niat pembelian (purchase intention) dalam aplikasi pemesanan perjalanan online dengan t-nilai 7,091. Citra merek (brand image) juga memiliki pengaruh terhadap niat beli dengan skor 5,253.

\section{Referensi}

[1] K. K. Wijaya, "GrabBike VS Go-Jek, Siapa yang Mencapai Pertumbuhan Paling Cepat?," 2015. [Online]. Available: https://id.techinasia.com/pertumbuhangrabbike-vs-go-jek. [Accessed: 01-Nov-2017].

[2] K. B. Mansour, K. Kooli, and R. Utama, "Online trust antecedents and their consequences on purchase intention: an integrative approach," J. Cust. Behav., vol. 13, no. 1, p. $25 \mathrm{e} 42,2014$.

[3] J. J. Wu, Y. H. Chen, and Y. S. Chung, "Trust factors influencing virtual community members: a study of transaction communities," J. Bus. Res., vol. 63, no. 9e10, p. $1025 \mathrm{e} 1032,2010$.

[4] P. McCole, E. Ramsey, and J. Williams, "Trust considerations on attitudes towards online purchasing: the moderating effect of privacy and security concerns," J Bus Res, vol. 63, no. 9, pp. 1018-1024, 2010.

[5] H. Kim, Y. Xu, and S. Gupta, "Which is more important in Internet shopping, perceived price or trust?," Electron Commer Res Appl, vol. 11, no. 3, pp. 241-252, 2012.

[6] E. J. Lee and J. W. Overby, "Creating value for online shoppers: implications for satisfaction and loyalty," $J$. Consum. Satisf. Dissatisfaction, Complain. Behav., vol. 17, p. 54e67, 2004.

[7] V. A. Zeithaml, "Consumer perceptions of price, quality, and value: a meansend model and synthesis of evidence," J. Mark., vol. 52, no. 3, p. 2e22, 1988.

[8] K. Ryu, H. Han, and T. H. Kim, "The relationships among overall quick-causal restaurant image, perceived value, customer satisfaction, and behavioral intentions," Int. J. Hosp. Manag., vol. 27, no. 3, p. 459e469, 2008.

[9] M. Aghekyan-Simonian, S. Forsythe, W. S. Kwon, and V. Chattaraman, "The role of product brand image and online store image on perceived risks and online purchase intentions for apparel," J. Retail. Consum. Serv., vol. 19, no. 3, p. 325e 331, 2012.

[10] A. Anwar, A. Gulzar, F. B. Sohail, and S. N. Akram, "Impact of brand image, trust, and affect on consumer brand extension attitude: the mediating role of brand loyalty," Int. J. Econ. Manag. Sci., vol. 1, no. 5, p. 73e79, 2011.

[11] N. Buaprommee and K. Polyorat, "The antecedents of purchase intention of meat with traceability in Thai consumers," Asia Pacific Manag. Rev., vol. 21, no. 3, pp. $161-169,2016$.

[12] Jamilah and P. W. Handayani, "Analysis on Effects of Brand Community on Brand Loyalty in the Social Media : A Case Study of An Online Transportation ( UBER )," in 2016 International Conference on Advanced Computer Science and Information Systems (ICACSIS), 2016.

[13] C. Wang, "The Influence of Electronic Word-of-Mouth on the Decision-making of Online Travel Booking," in 2016 International Symposium on Computer, Consumer and Control, 2016, pp. 934-937.

[14] E. Oktivera and F. A. W. Wirawan, "Analysis on The Implementation of Digital Marketing Towards Motorbike," in 2015 International Conference on Information Technology Systems and Innovation (ICITSI), 2015.

[15] M. Conyette, "Modeling Factors That Influence Online Travel Booking," in 2011 Proceedings of the International Conference on e-Business (ICE-B), 2011.

[16] A. A. G. A. Yana, H. . Rusdhi, and M. A. Wibowo, "Analysis of factors affecting design changes in construction project with Partial Least Square (PLS)," Procedia Eng., vol. 125, pp. 40 - 45, 2015.

[17] J. Hair, W. Blake, B. Babin, and R. Tatham, Multivariate data analysis. New Jersey: Prentice Hall, 2006.

[18] C. Fornell and D. Larcker, "Evaluating structural equation models with unobservable variables and measurement error," J. Mark. Res., vol. 18, no. 3, pp. 39-50, 1981.

[19] A. Izquierdo-Yusta, C. Olarte-Pascual, and E. ReinaresLara, "Attitudes toward mobile advertising among users versus non-users of the mobile Internet," Telemat. Informatics, vol. 32, pp. 355-366, 2015. 